\title{
Efficacy of intra-arterial lidocaine infusion in the treatment of cerulein-induced acute pancreatitis
}

\author{
Ryszard Antkowiak, ${ }^{1, A-F}$, Łukasz Antkowiak ${ }^{2, A-F}$, Sławomir Grzegorczyn ${ }^{3, B-D}$, Klaudia Nalik-Iwaniak, ${ }^{4, B, D}$, \\ Natalia Kabała ${ }^{5, B, D}$, Zbigniew Arent ${ }^{4, B}$, Edyta Warmusz-Reichman ${ }^{6, B}$, Katarzyna Stęplewska ${ }^{7, C}$, Paweł Domosławski, ${ }^{8, E, F}$

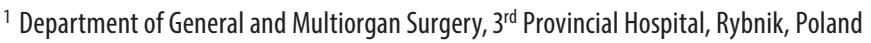 \\ 2 Department of Pediatric Neurosurgery, Medical University of Silesia, Katowice, Poland \\ ${ }^{3}$ Department of Biophysics, Medical University of Silesia, Zabrze, Poland \\ ${ }^{4}$ Experimental and Innovative Medicine Centre, University of Agriculture, Kraków, Poland \\ ${ }^{5}$ University Centre of Veterinary Medicine, University of Agriculture, Kraków, Poland \\ ${ }^{6}$ Department of Histology and Embryology, Medical University of Silesia, Zabrze, Poland \\ ${ }^{7}$ Department of Pathology, Institute of Medical Sciences, University of Opole, Poland \\ ${ }^{8}$ Department of General, Gastroenterological and Endocrine Surgery, Wroclaw Medical University, Poland \\ A - research concept and design; B - collection and/or assembly of data; $C$ - data analysis and interpretation; \\ $D$ - writing the article; $E$ - critical revision of the article; $F$ - final approval of the article
}

Address for correspondence

Łukasz Antkowiak

E-mail: lukaszantkowiak7@gmail.com

Funding sources

None declared

Conflict of interest

None declared

Received on April 6, 2020

Reviewed on April 22, 2020

Accepted on May 1, 2020

Published online on May 27, 2020

Cite as

Antkowiak R, Antkowiak Ł, Grzegorczyn S, et al. Efficacy of intra-arterial lidocaine infusion in the treatment of cerulein-induced acute pancreatitis. Adv Clin Exp Med. 2020:29(5):587-595. doi:10.17219/acem/121932

DOI

10.17219/acem/121932

Copyright

Copyright by Author(s)

This is an article distributed under the terms of the

Creative Commons Attribution 3.0 Unported (CC BY 3.0)

(https://creativecommons.org/licenses/by/3.0/)

\section{Abstract}

Background. Disturbances in pancreatic microcirculation, beginning with vasoconstriction, are crucial in early pancreatitis and progression to necrotizing pancreatitis. Thus, vascular-targeted treatment aiming to restore a sufficient level of microcirculation through vasodilation would possibly reduce the severity of pancreatitis. Lidocaine is an anti-arrhythmic and local anesthetic drug, which also acts as a vasodilator at higher concentrations.

Objectives. To evaluate the efficacy of intra-arterial infusion of lidocaine into the celiac trunk in treatment of cerulein-induced acute pancreatitis.

Material and methods. Wistar rats $(n=20)$ were randomly divided into 2 equal groups: the control group (NaCl group, $n=10$ ) and the study group (lidocaine group, $n=10)$. All subjects underwent surgical intervention with intra-arterial infusion of $0.9 \% \mathrm{NaCl}$ (control group) or $1 \%$ lidocaine hydrochloride (study group) into the celiac trunk. Blood samples were collected 5 times at regular intervals from each rat for amylase and lipase measurements. Histopathological analysis of the pancreas was performed.

Results. A total number of 16 rats (control group $n=7$, study group $n=9$ ) were included. In the postoperative course, the study group (lidocaine group) revealed lower values of serum amylase and lipase levels compared to the control group ( $\mathrm{NaCl}$ group), except the values at the ${ }^{15 t}$ treatment point, which appeared $1 \mathrm{~h}$ after intraoperative drug injection. Significantly lower treatment endpoint levels of pancreatic enzymes were seen in the lidocaine group. Moreover, no differences were observed between the $1^{\text {st }}$ and the last treatment point in the control group; however, these differences were significant for both enzymes in the study group. Histopathology revealed reduced pancreatitis severity in the study group compared to the controls.

Conclusions. Intra-arterial lidocaine infusion into the celiac trunk decreases pancreatitis severity. What is more, this study demonstrates the relevance of early vasodilation in the therapy of acute pancreatitis.

Key words: acute pancreatitis, lidocaine, regional arterial infusion, microcirculation 


\section{Introduction}

Acute pancreatitis is defined as an inflammatory process of the pancreas. ${ }^{1}$ The annual incidence of acute pancreatitis is 34 per 100,000 and is expected to increase. ${ }^{2,3}$ Severe pancreatitis associated with local and further systemic complications affects $20 \%$ of patients with acute pancreatitis. Mortality rises from $1.5 \%$ in mild to $5-17 \%$ in severe pancreatitis. ${ }^{4}$ These considerably increased rates indicate the necessity and importance of developing methods of preventing severe pancreatitis. Molecular mechanism indicates that acinar cell injury with subsequent intracellular activation of enzymes is a trigger of further autodigestion of pancreatic parenchyma and local inflammatory response. ${ }^{5}$ Consequent vessels injury causes increased vascular permeability with development of edema involving pancreatic parenchyma, vasoconstriction with long-lasting pancreatic hypoperfusion and ischemia, which can eventually lead to necrotizing pancreatitis. ${ }^{6}$ Acute pancreatitis can progress from local inflammatory response to systemic inflammatory response syndrome (SIRS), eventually leading to organ failure (OR). ${ }^{7}$ The pancreas is very sensitive to ischemia; hence, sufficient blood flow plays a very important role in its homeostasis and the prevention of inflammatory conditions. ${ }^{8}$ Moreover, there are studies indicating that patients with hypovolemia and shock were diagnosed with subclinical pancreatitis. ${ }^{6,9}$ Previous studies indicated that the decrease of pancreatic blood flow is an initial event in the development of acute pancreatitis. ${ }^{10,11}$ Early vasoconstriction is a trigger of further microvascular disturbances in the so-called ischemia-reperfusion phenomenon. ${ }^{12}$ They are said to be fundamental in the progression into severe and necrotizing pancreatitis and are described as crucial initiators of systemic inflammation. ${ }^{13}$ To our knowledge, no studies concerning targeted vasodilating treatment have been conducted. In order to induce vasodilation, lidocaine solution was infused intra-arterially. Lidocaine is an antiarrhythmic and local anesthetic drug, which, depending on its concentration, may have an absolutely distinct impact on vascular smooth muscle cells. Lidocaine is reported to have vasoconstricting action at low concentrations and acts as a vasodilator at higher concentrations. ${ }^{14}$ Thus, we hypothesized that infusion of lidocaine in the adequate dose would dilate arterioles and consequently reduce the severity and progression of pancreatitis. The aim of our study was to evaluate the efficacy of topical intra-arterial infusion of a high-concentration lidocaine solution into the celiac trunk in treating cerulein-induced acute pancreatitis in rats.

\section{Material and methods}

The experiment was conducted after the approval of II Local Ethical Committee for animal experiments operating at the Institute of Pharmacology of the Polish Academy of Sciences. All procedures were implemented in compliance with the Polish and European law (EU Directive 2010/63 on the protection of animals used for scientific purposes and the Act of January 15, 2015 on the protection of animals used for scientific or educational purposes).

\section{Animals and animal care conditions}

The project was carried out on a group of 20, 12-week old, male albino Wistar rats. The experiment was performed in Experimental and Innovative Medicine Centre at the University of Agriculture in Kraków, Poland. Rats were housed in the animal house in standardized conditions: temperature $20-24^{\circ} \mathrm{C}$, humidity $50-60 \%$, lighting 130-325 lux, and noise level $<30 \mathrm{~dB}$. Controlled lighting provided 12/12 light/dark cycle. Ventilation of the holding rooms ensured the air circulation with air exchange 10 times per hour. The environmental conditions were monitored on a daily basis. Rats were housed in conventional cages in groups of 2 compatible individuals. The cages were provided with nesting materials and environmental enrichments adapted to the species. Rats were provided with laboratory animal feed and water ad libitum. Animals were checked daily by a qualified person. All procedures were carried out by an adequately educated, trained and competent staff. Prior to the beginning of the project, the animals underwent 7-day quarantine. During this period, they were subjected to handling carried out by an experienced staff. After the quarantine, the rats were divided randomly into 2 equal groups: the control group $(\mathrm{NaCl}$ group, $\mathrm{n}=10$ ) and the study group (lidocaine group, $\mathrm{n}=10$ ).

\section{Animals inclusion criteria}

Rats were included in a postexperimental analysis if all of the following criteria were fulfilled: 1 ) no sudden death of uncertain origin within the time of the experiment; and 2) complete number of 5 blood samplings.

\section{Induction of acute pancreatitis}

All 20 animals after determination of body weight (b.w.) received subcutaneously $20 \mu \mathrm{g} / \mathrm{kg}$ b.w. cerulein every hour for 4 consecutive hours $(80 \mu \mathrm{g} / \mathrm{kg}$ b.w. in total per animal).

\section{Blood collection}

Blood samples for biochemical analyses of serum amylase and lipase levels were collected 5 times in case of each animal from both groups. Constantly for all measurements, a total volume of $0.2 \mathrm{~mL}$ blood was taken from the great saphenous vein or caudal vein. First sample (M1) was taken before cerulein injection to determine the reference values of serum amylase and lipase. Second sample (M2) was collected $6 \mathrm{~h}$ after the last cerulein injection in particular animal (at $10^{\text {th }} \mathrm{h}$ after beginning of cerulein administration 
Table 1. Blood sampling timing and their purposefulness. Point " 0 " indicates the moment before cerulein administration, when the blood was collected in order to establish the initial amylase and lipase levels

\begin{tabular}{|l|c|c|}
\hline Sample & $\begin{array}{c}\text { Blood tests } \\
\text { time point }\end{array}$ & $\begin{array}{c}\text { Aim of the sampling } \\
\text { M1 }\end{array}$ \\
\hline M2 & $10^{\text {th }}$ & $\begin{array}{r}\text { enzymes initial levels (reference) } \\
\text { enzymes levels at the point } \\
\text { when pancreatitis was already evoked } \\
\text { - just before intraoperative drug infusion }\end{array}$ \\
\hline M3 & $11^{\text {th }}$ & $\begin{array}{c}\text { enzymes levels } 1 \text { h after operation } \\
\text { (the } 1^{\text {st }} \text { treatment point) }\end{array}$ \\
\hline M4 & $13^{\text {th }}$ & $\begin{array}{r}\text { enzymes levels } 3 \text { h after operation } \\
\text { (the } 2^{\text {nd }} \text { treatment point) }\end{array}$ \\
\hline M5 & $15^{\text {th }}$ & $\begin{array}{r}\text { enzymes levels } 5 \text { h after operation } \\
\text { (treatment endpoint) }\end{array}$ \\
\hline
\end{tabular}

in each rat). Immediately after that, blood sampling surgery was started and then an intraoperative drug infusion was made. After termination of the surgery, the following blood tests were performed: $1 \mathrm{~h}$ (M3), $3 \mathrm{~h}$ (M4) and $5 \mathrm{~h}$ (M5) after intraoperative intra-arterial application of adequate solution ( $\mathrm{NaCl}$ in controls, lidocaine in study group). The summary of blood collection procedure is presented in Table 1.

\section{General anesthesia procedure}

The surgical procedures were carried out under general anesthesia. After applying a dose of $10 \mathrm{mg} / \mathrm{kg}$ b.w. ketamine (Bioketan; Vetoquinol Biowet, Gorzów Wielkopolski, Poland), the rats were given isoflurane (Isotek; Laboratorios Karizoo, Barcelona, Spain) during the whole procedure. The animals were treated with preemptive and postoperative analgesia - a dose of $0.05 \mathrm{mg} / \mathrm{kg}$ b.w. buphrenorfine (Bupaq; Richter Pharma, Wels, Austria).

\section{Surgical procedure and intraoperative injection of $\mathrm{NaCl} /$ lidocaine}

Under general anesthesia, in order to open the abdominal cavity, a $5 \mathrm{~cm}$ long skin incision extending from the xiphoid process was performed. After bowel irrigation, the inferior vena cava was exposed and protected from desiccation. Guided by vena cava location, which was left laterally, deeper penetration into abdominal cavity exposed the abdominal aorta with its branches (celiac trunk, superior mesenteric artery, renal arteries). Superiorly to the point where the celiac trunk branches and superiorly to the superior mesenteric artery branch, the aorta was freed from adhesions and prepared for temporal aorta occlusion with the insertion of suspensions (superiorly and inferiorly to celiac trunk branch). Subsequently, 2 vascular clamps were inserted in the prepared places in order to close the aorta completely, with the celiac trunk branch being located in the middle between these clamps, thus enabling injection. Preoperatively prepared $0.9 \% \mathrm{NaCl}$ solution $(0.5 \mathrm{~mL} / \mathrm{kg}$ b.w. $)$ in the control group and a $1 \%$ lidocaine hydrochloride solution $(5 \mathrm{mg} / \mathrm{kg}$ b.w. accounting for $10^{4} \mu \mathrm{g} / \mathrm{mL}$ drug concentration) in the experimental group was injected slowly, exactly in the area of celiac trunk branching, within the timespan of approx. $1 \mathrm{~min}$. Hemostatic materials were placed on the injection point immediately after the needle was extracted and the vascular clamps were subsequently removed from the aorta. Hemostatic materials were applied for around 3-5 min to support hemostasis and, after ascertaining that the bleeding stopped, the abdominal cavity was prepared for closure with hemostatics left inside. The skin was closed using single non-absorbable sutures. Surgical intervention was complete.

\section{Euthanasia}

After the last blood collection, the animals were euthanized with an anesthetic overdose. They were subjected to isoflurane and then a lethal dose of $300 \mathrm{mg} / \mathrm{kg}$ b.w. pentobarbital (Morbital; Biowet Puławy, Puławy, Poland) was administered. After confirming the cessation of vital signs, laparotomy was conducted to collect the pancreas from each animal for further histopathological examination.

\section{Histopathological examination}

The pancreas of each rat was fixed with a standard method in $10 \%$ formalin solution and embedded in paraffin blocks. Slices, $5 \mu \mathrm{m}$ in thickness, were cut and routinely stained with hematoxylin and eosin (H\&E). Histologic examination was carried out by an experienced pathologist who was unaware of the distribution of subjects in each group. Histopathologic examination assessed semi-quantitatively the extent of necrosis, edema, hemorrhage, vacuolization, and leukocyte infiltration, as it was described in the previous study. ${ }^{15}$ The following scale was used to evaluate the severity of these features: 0 - feature was not observed, no changes, 1 - mild changes, 2 - moderate changes, 3 - severe changes.

\section{Statistical analysis}

The statistical analysis was performed with the use of STATISTICA v. 13.1 software (StatSoft, Inc., Tulsa, USA). The normality of the variable distributions was tested using the Shapiro-Wilk test.

The t-test for independent variables was performed to test the differences between the means of the study and the control groups. The non-parametric Mann-Whitney U test was used in cases where one of the comparable variables was lacking normality. The nonparametric Friedman analysis of variance (ANOVA) test for repeatable measurements was used to determine the statistical significance of differences in a series of dependent variables of the control or study group. The significance level $\alpha<0.05$ was adopted. 


\section{Results}

Sixteen Wistar rats (control group $\mathrm{n}=7$, study group $n=9$ ) were finally included in the study and further analysis. Four animals ( 3 from the control group and 1 from study group) from 20 participating had to be excluded from the study because of early death, which precluded the possibility of obtaining a complete number of 5 measurements. Serum amylase and lipase levels for both groups: control ( $\mathrm{NaCl}$ group) and study (lidocaine group) are presented in Tables 2 and 3. No statistical significance

Table 2. Amylase values measurements in the control and the study group through the entire preoperative (M1-M2) and postoperative course (M3-M5)

\begin{tabular}{|l|c|c|c|c|}
\multirow{2}{*}{$\begin{array}{c}\text { Blood } \\
\text { sample }\end{array}$} & \multicolumn{2}{|c|}{$\begin{array}{c}\text { Control group } \\
\text { (NaCl group) }\end{array}$} & \multicolumn{2}{|c}{$\begin{array}{c}\text { Study group } \\
\text { (lidocaine group) }\end{array}$} \\
\cline { 2 - 5 } & mean [U/L] & SD [U/L] & mean [U/L] & SD [U/L] \\
\hline M1 & 651.43 & 83.57 & 645.56 & 51.979 \\
\hline M2 & 39933 & 15103 & 49357 & 5776 \\
\hline M3 & 17969 & 4862 & 18691 & 3142.2 \\
\hline M4 & 15974 & 3219 & 15311 & 868 \\
\hline M5 & 16010 & 6412 & 10488 & 1247.5 \\
\hline
\end{tabular}

SD - standard deviation.

Table 3. Lipase values measurements in the control and the study group through the entire preoperative (M1-M2) and postoperative course (M3M5)

\begin{tabular}{|l|c|c|c|c|}
\multirow{2}{*}{$\begin{array}{c}\text { Blood } \\
\text { sample }\end{array}$} & \multicolumn{2}{|c|}{$\begin{array}{c}\text { Control group } \\
\text { (NaCl group) }\end{array}$} & \multicolumn{2}{|c}{$\begin{array}{c}\text { Study group } \\
\text { (lidocaine group) }\end{array}$} \\
\cline { 2 - 5 } & mean [U/L] & SD [U/L] & mean [U/L] & SD [U/L] \\
\hline M1 & 10.29 & 1.92 & 9.52 & 1.273 \\
\hline M2 & 1860.7 & 886.38 & 2090.3 & 371.54 \\
\hline M3 & 743.56 & 217.44 & 681.21 & 186.229 \\
\hline M4 & 605.74 & 107.49 & 498.48 & 109.248 \\
\hline M5 & 568.31 & 228.43 & 262.48 & 59.486 \\
\hline
\end{tabular}

SD - standard deviation.

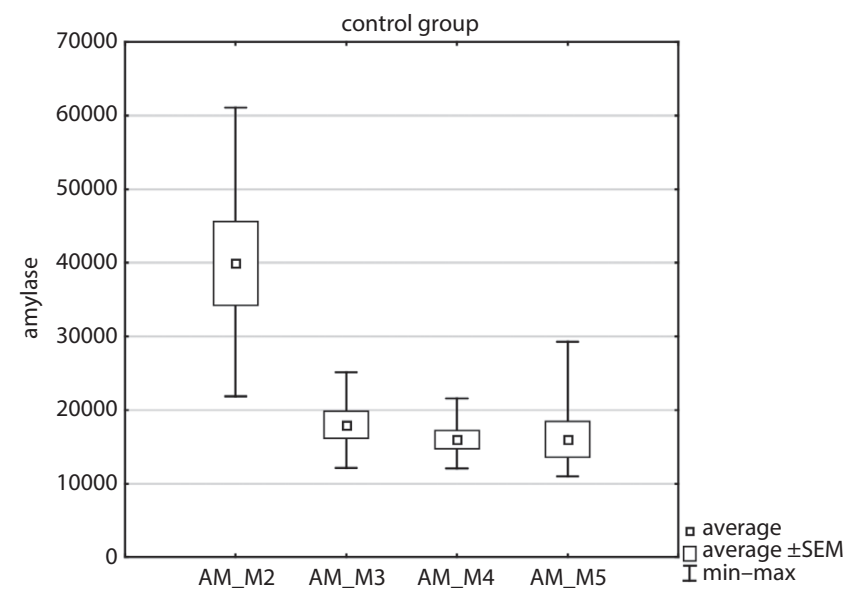

Fig. 1. Kinetics of amylase values in the control group measured from pancreatitis point (M2) through entire postoperative course (M3-M5)
Table 4. Comparison of amylase and lipase levels between the control and the study group before induction of pancreatitis (M1), when pancreatitis was evoked (M2) and at the treatment endpoint (M5)

\begin{tabular}{|l|c|c|c|c|c|}
\multirow{2}{*}{ Variable } & \multicolumn{2}{|c|}{$\begin{array}{c}\text { Control group } \\
\text { (NaCl group) }\end{array}$} & \multicolumn{2}{|c|}{$\begin{array}{c}\text { Study group } \\
\text { (lidocaine group) }\end{array}$} & \multirow{2}{*}{ p-value } \\
\cline { 2 - 5 } & $\begin{array}{c}\text { mean } \\
{[\mathrm{U} / \mathrm{L}]}\end{array}$ & $\begin{array}{c}\mathrm{SD} \\
{[\mathrm{U} / \mathrm{L}]}\end{array}$ & $\begin{array}{c}\text { mean } \\
{[\mathrm{U} / \mathrm{L}]}\end{array}$ & $\begin{array}{c}\text { SD } \\
{[\mathrm{U} / \mathrm{L}]}\end{array}$ & \\
\hline Amylase M1 & 651.43 & 83.57 & 645.56 & 51.979 & 0.9182 \\
\hline Lipase M1 & 10.29 & 1.92 & 9.52 & 1.273 & 0.1416 \\
\hline Amylase M2 & 39933 & 15103 & 49357 & 5776 & 0.2105 \\
\hline Lipase M2 & 1860.7 & 886.3 & 2090.3 & 371.54 & 0.5360 \\
\hline Amylase M5 & 16010 & 6412 & 10488 & 1247.5 & $\mathbf{0 . 0 0 5 9 2 1}$ \\
\hline Lipase M5 & 568.31 & 228.43 & 262.48 & 59.49 & $\mathbf{0 . 0 0 1 6 4 5}$ \\
\hline
\end{tabular}

SD - standard deviation; bold values denote statistical significance at the $p<0.05$ level.

was found in the initial enzymes levels (M1, reference enzyme levels) between the 2 groups and in the levels after the induction of pancreatitis (M2) between 2 groups as well (Table 4). Differences in M2-M5 series were significant in both control (amylase $\mathrm{p}<0.05$; lipase $\mathrm{p}<0.05$ ) and the study group (amylase $\mathrm{p}<0.05$; lipase $\mathrm{p}<0.05$ ); however, differences checked in M3-M5 series revealed significance only in the study group (Table 5 ). That observation indicates that the significance obtained in M2-M5 series in the controls is caused mainly by a parameter drop between M2 and M3 (Fig. 1-4). Significant differences between M4 and M5 only in the study group reveal the general decreasing tendency in the pancreas inflammation parameters (Fig. 5,6).

Intergroup comparison of M5 parameters (Table 4) showed significant differences for both amylase (controls mean: 16,010 U/L; study mean: 10,488 U/L) and lipase (controls mean: 568.31 U/L; study mean: 262.48 U/L). Moreover, no differences were observed between the $1^{\text {st }}$ treatment point (M3) and the last treatment point (M5) in the control group; however, these differences were significant

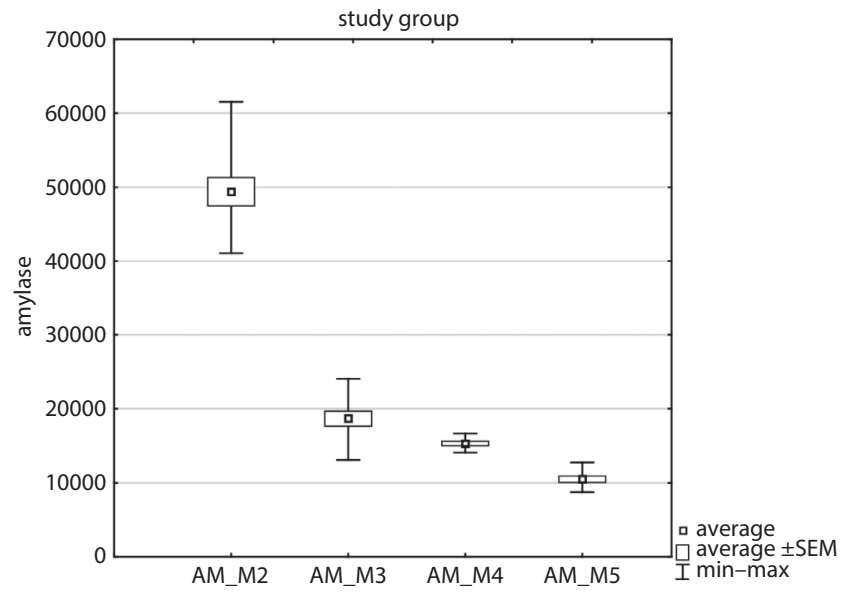

Fig. 2. Kinetics of amylase values in the study group measured from pancreatitis point (M2) through entire postoperative course (M3-M5) 


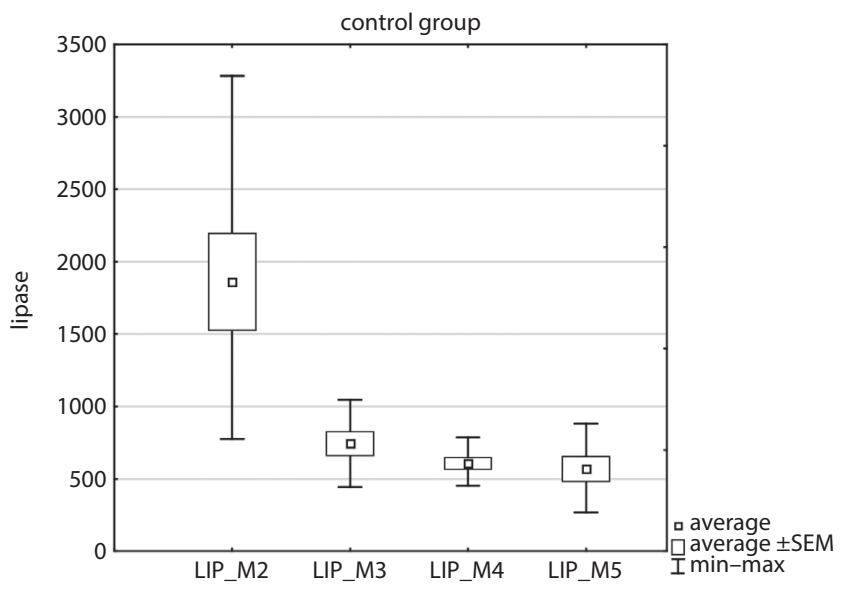

Fig. 3. Kinetics of lipase values in the control group measured from pancreatitis point (M2) through entire postoperative course (M3-M5)

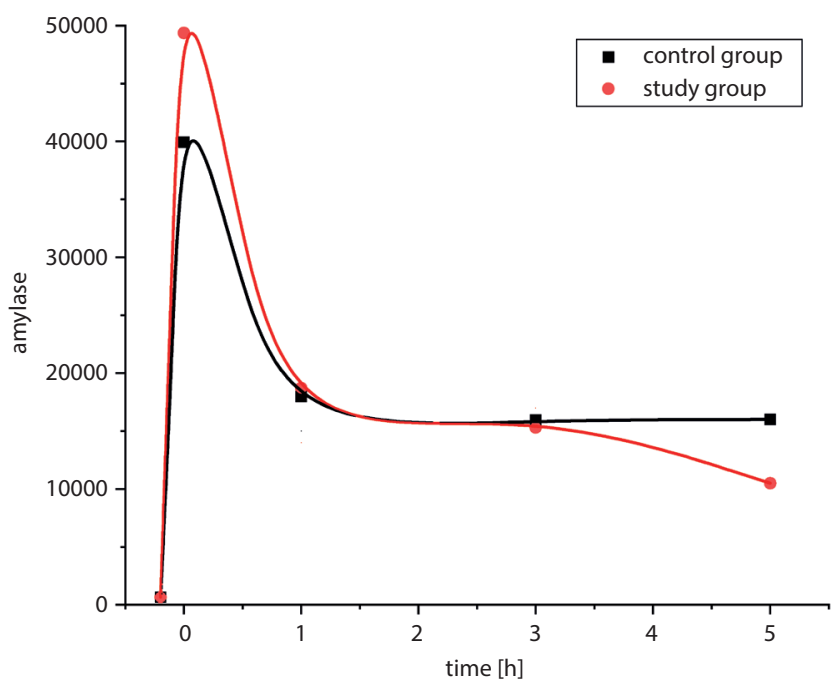

Fig. 5. Differences of amylase absolute values between control and study group in the entire preoperative (M1-M2) and postoperative course (M3-M5)

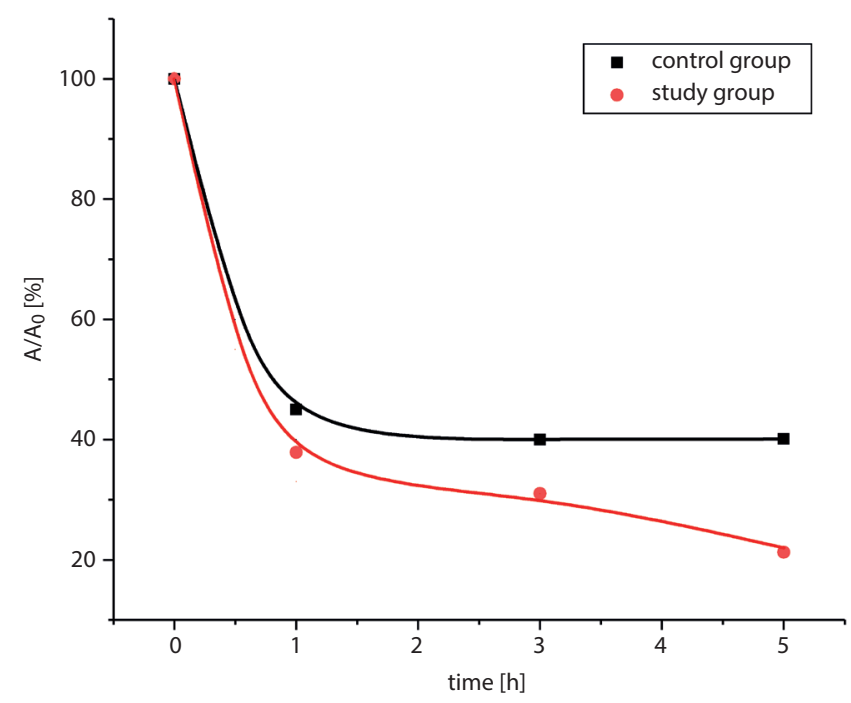

Fig. 7. Percentage differences of amylase values between control and study group in the entire postoperative course (M3-M5) with reference to values obtained at pancreatitis point (M2)

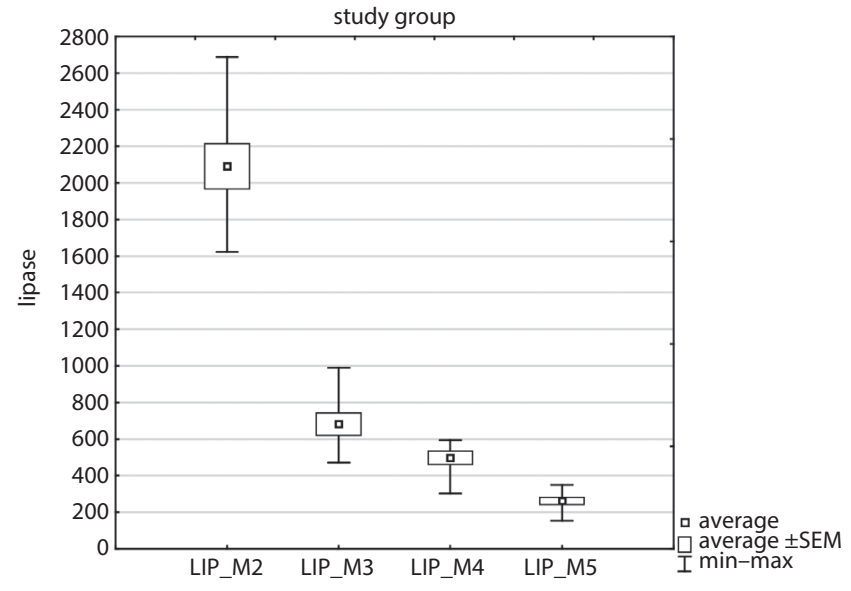

Fig. 4. Kinetics of lipase values in the study group measured from pancreatitis point (M2) through entire postoperative course (M3-M5)

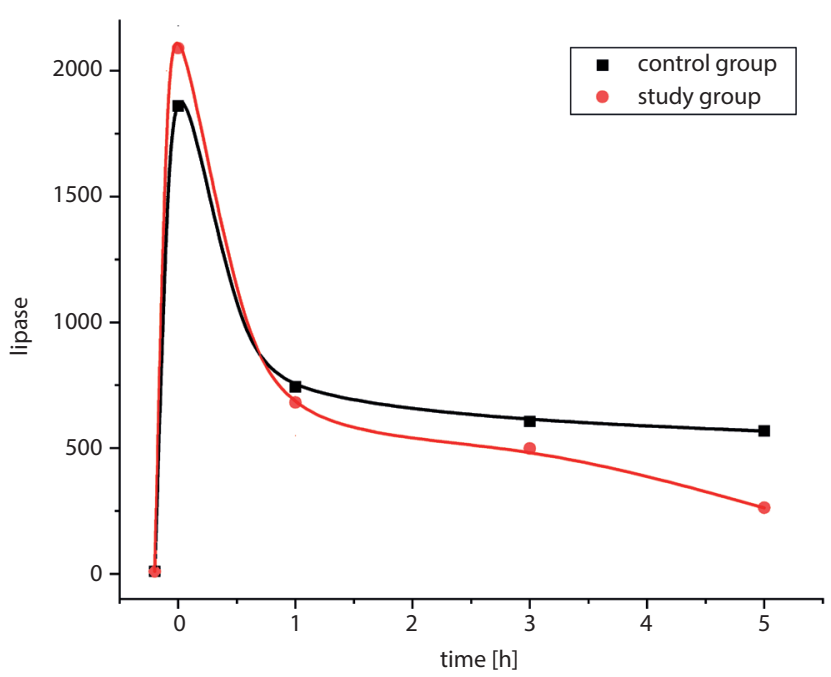

Fig. 6. Differences of lipase absolute values between control and study group in the entire preoperative (M1-M2) and postoperative course (M3-M5)

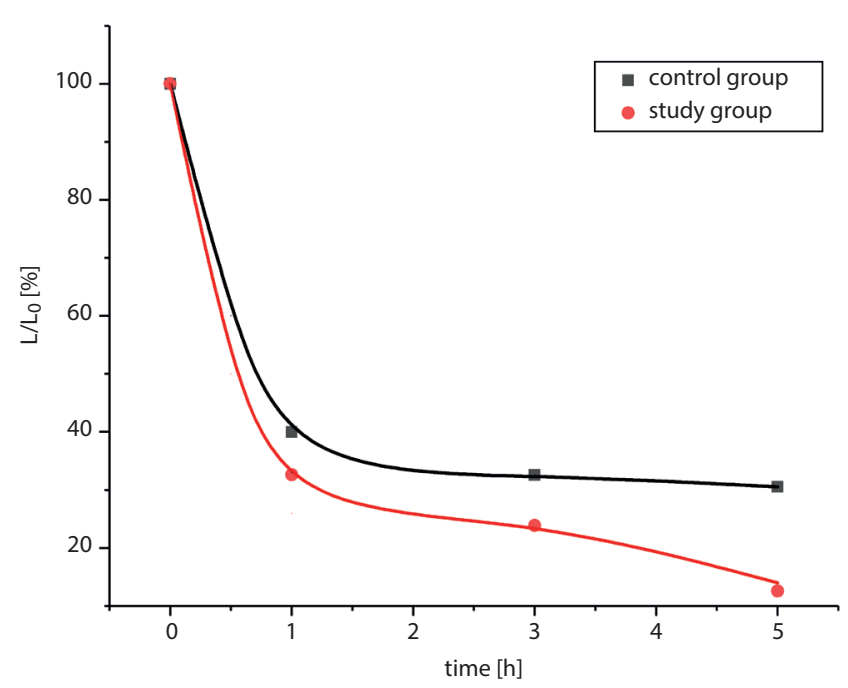

Fig. 8. Percentage differences of lipase values between control and study group in the entire postoperative course (M3-M5) with reference to values obtained at pancreatitis point (M2) 
Table 5. Statistical analysis of intragroup differences between both enzyme levels in the particular periods. M2-M5 are values from pancreatitis point until the treatment endpoint; M3-M5 are values from the $1^{\text {st }}$ treatment point until the treatment endpoint; $M 2-M 3$ are values from the pancreatitis point until the $1^{\text {st }}$ treatment point; $M 3-M 4$ are values from the $1^{\text {st }}$ treatment point until the $2^{\text {nd }}$ treatment point; M4-M5 are values from the $2^{\text {nd }}$ treatment point until the last treatment point

\begin{tabular}{|c|c|c|c|c|}
\hline \multirow{3}{*}{$\begin{array}{c}\text { Series of } \\
\text { measurements }\end{array}$} & \multicolumn{2}{|c|}{ Amylase } & \multicolumn{2}{|c|}{ Lipase } \\
\hline & $\begin{array}{l}\text { control } \\
\text { group } \\
\text { (NaCl } \\
\text { group) }\end{array}$ & $\begin{array}{l}\text { study } \\
\text { group } \\
\text { (lidocaine } \\
\text { group) }\end{array}$ & $\begin{array}{l}\text { control } \\
\text { group } \\
\text { (NaCl } \\
\text { group) }\end{array}$ & $\begin{array}{c}\text { study } \\
\text { group } \\
\text { (lidocaine } \\
\text { group) }\end{array}$ \\
\hline & \multicolumn{4}{|c|}{$p$-values } \\
\hline M2-M5 & 0.00197 & 0.00001 & 0.00319 & 0.00001 \\
\hline M3-M5 & 0.15612 & 0.00030 & 0.249655 & 0.00030 \\
\hline$M 2-M 3$ & 0.006693 & 0.000000 & 0.012695 & 0.000003 \\
\hline M3-M4 & 0.02982 & 0.01963 & 0.080211 & 0.01963 \\
\hline M4-M5 & 0.735317 & 0.00270 & 0.742494 & 0.00270 \\
\hline
\end{tabular}

Bold values denote statistical significance at the $p<0.05$ level.

Table 6. Comparison between the $1^{\text {st }}$ treatment point (M3) and the last treatment point (M5) in both groups for both enzyme values

\begin{tabular}{|l|c|c|c|c|}
\multirow{2}{*}{ Variable } & \multicolumn{2}{|c|}{$\begin{array}{c}\text { Control group } \\
\text { (NaCl group) }\end{array}$} & \multicolumn{2}{|c|}{$\begin{array}{c}\text { Study group } \\
\text { (lidocaine group) }\end{array}$} \\
\cline { 2 - 5 } & mean & p-value & mean & p-value \\
\hline Amylase M3 & 17969 & 0.498963 & 18691 & $\mathbf{0 . 0 0 2 7 0}$ \\
\hline Amylase M5 & 16010 & & 10488 & \\
\hline Lipase M3 & 743.56 & 0.249655 & 681.2 & $\mathbf{0 . 0 0 2 7 0}$ \\
\hline Lipase M5 & 568.31 & & 262.5 & \\
\hline
\end{tabular}

Bold values denote statistical significance at the $p<0.05$ level.

in the study group (Table 6), thus clearly indicating that the study group (lidocaine group) responded much better to the given therapy than the control group ( $\mathrm{NaCl}$ group).

According to Fig. 7, the decrease in amylase levels from the induction of pancreatitis (M2) to the final treatment point (M5) amounted to $60 \%$ in the control group and $79 \%$ in the study group. Respectively, lipase decrease reached $70 \%$ in the $\mathrm{NaCl}$ group and $87 \%$ in the lidocaine group (Fig. 8).

Histopathological analysis revealed lower intensity of necrosis, edema, hemorrhage, and vacuolization in the study group compared to the control group. However, leukocyte infiltration was similar in both groups (Fig. 9,10). Results of histopathological examination of all pancreatic tissue specimens from both groups, presented as ranges of values of assessed features, are shown in Table 7.

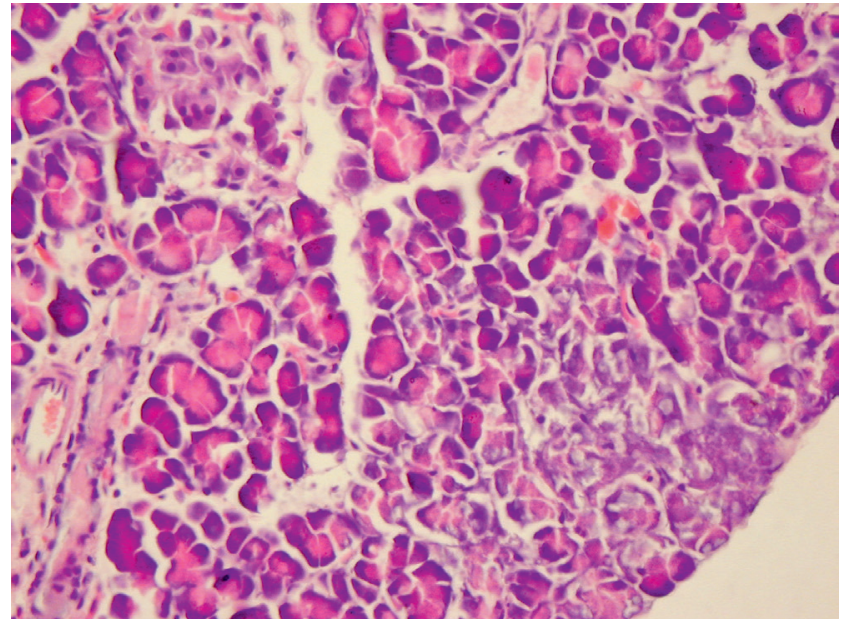

Fig. 9. Pancreas with necrosis and edema in the control group ( $H \& E$, magnification $\times 400$ )

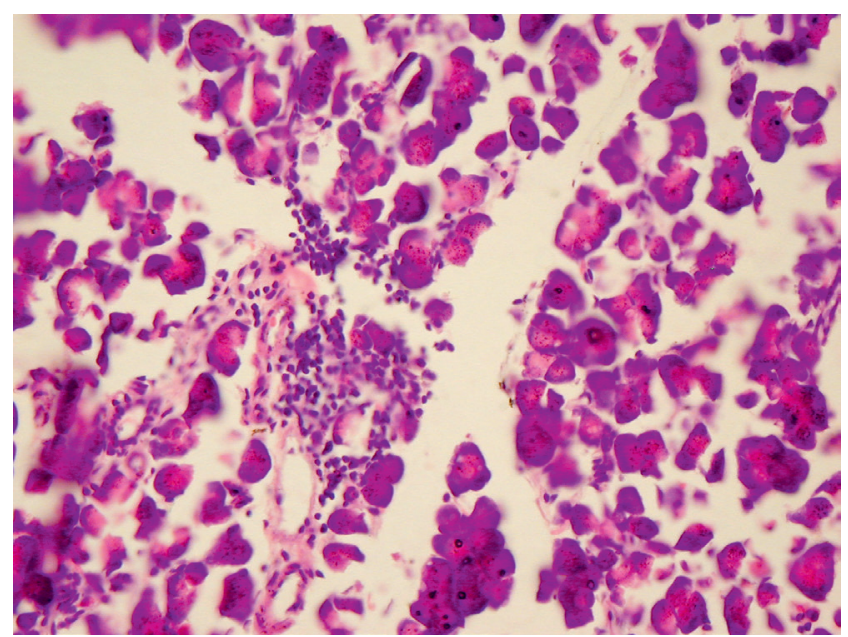

Fig. 10. Pancreas with leukocyte infiltration in the study group (H\&E, magnification $\times 200)$

\section{Discussion}

Lidocaine is a local anesthetic and antiarrhythmic drug, which additionally has a dual action on vessels. It causes vasoconstriction at low drug concentrations $\left(10^{3} \mu \mathrm{g} / \mathrm{mL}\right.$ and lower), but acts as a vasodilator at higher concentrations $\left(10^{4} \mu \mathrm{g} / \mathrm{mL}\right) .{ }^{14,16}$ Newton et al. indicated that vasodilation caused by lidocaine can also be mediated by the local production of nitric oxide in endothelium. ${ }^{17}$ Furthermore, lidocaine has an anti-inflammatory activity, thus reducing cytokine-induced injury of endothelial and vascular

Table 7. Ranges of values of microscopic features severity in pancreas H\&E specimens in the control and the study group

\begin{tabular}{|l|c|c|c|c|}
\multicolumn{1}{|c|}{ Group } & Necrosis & Edema & Hemorrhage & Vacuolization \\
\hline Control group $(n=7)$ & $0-2$ & $0-2$ & $0-3$ & $0-3$ \\
\hline Study group $(n=9)$ & $0-1$ & $0-1$ & $0-1$ & $0-2$ \\
\hline
\end{tabular}

H\&E - hematoxylin and eosin. 
smooth muscle cells. It has already been reported that mitochondrial adenosine triphosphate-sensitive potassium channels (KATP), which are present in both endothelial and vascular smooth muscle cells, mediate cellular protection. ${ }^{18}$ Lidocaine induces KATP channels activity and, thereby, functions as an important anti-apoptotic factor. Vasodilating and cell-protecting properties of lidocaine have a positive impact on endothelial and vascular smooth muscle cells; hence, the application of that drug is an effective means of preventing pancreatic tissue hypoperfusion and subsequent irreversible exacerbation of pancreatitis. Due to the dual action of lidocaine, topical application was performed to gain the highest possible concentration in the pancreatic microcirculation. Action of intravenously administered lidocaine on vessels was described by Johns et al. and resulted in vasoconstriction. ${ }^{14}$ Moreover, local intra-arterial infusion of lidocaine solution at concentration of $10^{3} \mu \mathrm{g} / \mathrm{mL}$ and lower caused considerable vasospasm too. Thus, we applied lidocaine solution at $10^{4} \mu \mathrm{g} / \mathrm{mL}$ concentration which was previously confirmed to cause significant dilation of arterioles. ${ }^{14}$ This study was conducted using currently available intra-arterial drug administration method known as Continuous Regional Arterial Infusion (CRAI). The CRAI is a therapeutic method introduced in Japan in 1996. Its advantage over the intravenous method comes from the possibility of applying local intra-arterial infusion of selected substance, and gaining almost 10 times higher drug concentration in the pancreatic vessels. ${ }^{19}$ Many studies concerning the difference between CRAI and the intravenous method indicated univocally the advantage of CRAI in acute pancreatitis therapy. ${ }^{19,20}$ Taking into consideration the dual action of lidocaine, intra-arterial CRAI method was chosen to obtain high lidocaine concentrations in the celiac trunk, this ultimately led to vasorelaxation of arterioles in pancreatic microcirculation.

The pathophysiology of acute pancreatitis is substantially understood; however, exact cellular mechanisms are still not completely known. ${ }^{21}$ There is a consensus that intraacinar trypsinogen activation is a trigger of pancreatic tissue injury, finally resulting in activation of enzymes stored in granules. ${ }^{22}$ Furthermore, some authors indicate that activation of NFKB in acinar cells is the second major parallel mechanism observed in the early pancreatitis. ${ }^{5}$ Moreover, activation of NFKB is the most important factor inducing inflammation in pancreatitis and is also responsible for subsequent systemic inflammatory response. ${ }^{23}$ These 2 pathways seem to be initiated independently. Trypsinogen-activation induces pancreatic damage and acinar cell death in early stages; however, NFkB-modulated inflammation is essential in later phases. ${ }^{24}$ Enzyme-induced acinar cell injury leads to outflow of digestive enzymes into parenchyma, causing autodigestion of pancreatic tissue and injury to the vessels. ${ }^{7}$ Subsequent inflammation-induced disturbances of pancreatic vessels are crucial for disease progression. Early endothelial injury leads to changes in the structure of pancreatic arterioles by initiating increased permeability, thrombi formation and release of vasoconstricting endothelin. ${ }^{18,25,26}$ The pancreas is extremely susceptible to ischemia. Some studies revealed subclinical pancreatitis in patients with hypovolemia or shock. ${ }^{9}$ That mechanism can be explained by the characteristics of pancreatic microcirculation. Every pancreatic lobule is supplied by a single arteriole, which branches after entering the lobule. The interlobular artery has no anastomoses with other vessels and is described as an end artery. ${ }^{22}$

Vasoconstriction seems to be an early event of pancreatitis, which inevitably leads to ischemia, necrosis, circulatory obstruction, and systemic complications. ${ }^{27,28}$ A study conducted by Klar et al. confirms the presence of arterioles vasoconstriction, which is visible in the direct area of pancreatitis. These findings were visualized using low contrast enhancement in the computed tomography. This method additionally confirmed histologically observed microcirculatory disturbances. ${ }^{11}$ Zhou et al. stated that an arteriolar sphincter injury caused by the inflammatory process in the pancreatic parenchyma leads to vasospasms and is the primary factor of microcirculation disturbances. Pancreatic edema and intravascular emboli are followed by secondary changes, appearing after arteriolar sphincter injury. ${ }^{29}$ Disturbances in microcirculation, despite being already present in mild pancreatitis, are characteristic for severe acute pancreatitis. In the latter phase, however, they are no longer associated with reversible changes in the pancreas. The mechanism called ischemia-reperfusion is an early occurring event responsible for further pancreatic hypoperfusion in acute pancreatitis. It is believed to be a crucial factor in the gradual progression of pancreatitis severity. Vasospasm affecting precapillary arterioles is responsible for early pancreatitis phase - ischemia. ${ }^{12}$ Nitric oxide as a potent vasodilating factor is released by an intact endothelium. It affects the conditions of the vessels and reduces prothrombotic events. ${ }^{30}$ Endothelial injury induces the production of endothelin, which is known to be a long-acting vasoconstrictor. ${ }^{25}$ Imbalance between nitric oxide and endothelin plays a crucial role in the previously described induction of vasospasm. ${ }^{12}$ Additionally, trypsin, elastase, phospholipase $\mathrm{A}_{2}$, and activated neutrophils subsequently increase vascular permeability both locally and systemically. ${ }^{31,32}$ Erosions in the vascular walls, caused by released pancreatic enzymes, are responsible for the occurrence of significant vasospasm, reduction of pancreatic blood flow, induction of hypercoagulability, and elevation in blood viscosity resulting in substantial pancreas hypoperfusion. ${ }^{6}$ Topical loss of endothelial barrier mechanisms can allow blood and large molecules such as activated proteases to infiltrate the pancreatic tissue, causing further cell injury, local pancreatic hemorrhages and pancreatic edema. ${ }^{7}$ Systemic changes in vascular permeability considerably distort central hemodynamics in severe acute pancreatitis by increasing extravascular fluids penetration, which leads to ascites, pleural exudation, 
hypotony, and eventually shock. ${ }^{33}$ Adhesion of leukocytes to the endothelium especially in postcapillary venules is not present in the vasoconstricting - ischemic - phase. It only appears in the second, reperfusion-vasodilating - phase. ${ }^{12,22}$ Reperfusion with oxygen inflow induces production of free radicals and leukocyte activation. It is also suggested that leukocyte, and platelets destroy pancreas in the reperfusion phase and are responsible for noticeable worsening of the disease course. ${ }^{12}$ Furthermore, shortterm vasoconstriction causes reversible changes in pancreatic morphology and physiology, while a long-lasting spasm leads to irreversible histological changes and necrotizing pancreatitis. ${ }^{25}$ Our study demonstrates that early improvement of pancreatic microcirculation by induced vasodilation could be a beneficial and promising therapy; however, it requires further validation. We found out that histological changes, such as necrosis, edema and hemorrhages, were more prevalent in the control group than in the study group (lidocaine group). The presented results indicate that vasodilation caused by lidocaine decreased disease severity. These findings confirm the necessity of prompt vasodilation at the early stage of pancreatitis in order to prevent irreversible microcirculatory changes in the pancreas. According to demonstrated pathophysiology of acute pancreatitis, vasodilation should be considered the primary treatment option. It is worth mentioning that improved hypoperfusion is associated with lower levels of trypsinogen activation peptide, which correlates with the severity of pancreatitis. ${ }^{4}$ Microvascular disturbances are not limited only to the pancreas. It is suggested that systemic inflammatory response syndrome (SIRS) and subsequent organ failure (OR) derive from intensive and prolonged intrapancreatic leukocyte-endothelium interactions, hypercoagulability, thrombi formation, and an increase in platelet count. , $^{8,34}$

These factors are likely to influence the condition of other organs, which has already been confirmed by thrombi found in the vascular bed of the spleen and lungs. ${ }^{35}$

To date, only a few studies dealing with the improvement of pancreatic blood flow were performed. ${ }^{36,37}$ However, to our knowledge, this is the first study of a new method that aims to restore adequate microcirculation by vasodilation, and enables effective treatment at the first phase of pancreatitis. Vascular disturbances seem to be crucial in the development and progression of acute pancreatitis with further systemic complications. Thus, numerous authors indicate the relevance of pancreatic blood flow improvement. ${ }^{10,12,22,29,38}$ Previous studies focused on restoring sufficient vascular architecture by administering heparin, endothelin receptor antagonists and PAF, or by performing aggressive fluid resuscitation. ${ }^{6} \mathrm{Ke}$ et al. indicated the important role of low-molecular-weight heparin in attenuating necrosis and restoring pancreatic perfusion, which leads to the improvement of microcirculation. ${ }^{36}$ Endothelin participates in the progression of pancreatitis by its vasoconstricting action and subsequent hypoperfusion. ${ }^{33,38,39}$ It was shown that blockage of endothelin receptor (ET-A) increases blood flow and decreases vascular permeability. ${ }^{37}$ Bradykinin and PAF antagonists were linked with decreased pancreatitis severity, also owing to the improvement of pancreatic blood flow, a decrease in vascular permeability and a reduction of leukocyte adhesion. ${ }^{6,22}$ Fluid therapy, when initiated in a very early stage of pancreatitis, can presumably improve clinical course by enhancing microcirculation. ${ }^{40}$ These experimental methods, although promising, need further validation and their effectiveness should be compared with lidocaine efficacy. We hypothesize that a combination of lidocaine with some of the other previously tested drugs can presumably turn out to be more effective than therapy with lidocaine alone. This could be explained by the feasible increase in the availability of infused therapeutics due to enhanced pancreatic blood flow caused by vasodilating action of lidocaine. We hope that our findings will contribute to introducing an innovative acute pancreatitis treatment method.

\section{Conclusions}

Intra-arterial lidocaine infusion into the celiac trunk decreases pancreatitis severity. What is more, this study demonstrates the relevance of early vasodilation induction in the therapy of acute pancreatitis. To our knowledge, this is the first study describing a new method that aims to restore adequate pancreatic blood flow by inducing vasodilation in the early, vasoconstricting phase of acute pancreatitis. Further comparative human studies need to be conducted in order to precisely assess the long-term therapeutic effect of lidocaine and to confirm the efficacy of this method in treating acute pancreatitis.

\section{ORCID iDs}

Ryszard Antkowiak (1) https://orcid.org/0000-0003-1377-1608 Łukasz Antkowiak (1) https://orcid.org/0000-0003-0145-4680 Sławomir Grzegorczyn (1) https://orcid.org/0000-0002-5248-3505 Klaudia Nalik-Iwaniak (1) https://orcid.org/0000-0003-3140-7172 Natalia Kabała (1) https://orcid.org/0000-0001-5707-7349

Zbigniew Arent (10) https://orcid.org/0000-0002-5997-2555

Edyta Warmusz-Reichman (1) https://orcid.org/0000-0002-1061-807X

Katarzyna Stęplewska (1) https://orcid.org/0000-0002-0971-2317

Paweł Domosławski (1) https://orcid.org/0000-0003-1903-0843

\section{References}

1. Goodchild G, Chouhan M, Johnson GJ. Practical guide to the management of acute pancreatitis. Frontline Gastroenterol. 2019;10(3): 292-299. doi:10.1136/flgastro-2018-101102

2. Machicado JD, Papachristou GI. Pharmacologic management and prevention of acute pancreatitis. Curr Opin Gastroenterol. 2019;35(5): 460-467. doi:10.1097/MOG.0000000000000563

3. Garg PK, Singh VP. Organ failure due to systemic injury in acute pancreatitis. Gastroenterology. 2019;156(7):2008-2023. doi:10.1053/j.gastro.2018.12.041

4. Chatila AT, Bilal M, Guturu P. Evaluation and management of acute pancreatitis. World J Clin Cases. 2019;7(9):1006-1020. doi:10.12998/ wjcc.v7.i9.1006 
5. Sah RP, Garg P, Saluja AK. Pathogenic mechanisms of acute pancreatitis. Curr Opin Gastroenterol. 2012;28(5):507-515. doi:10.1097/ MOG.0b013e3283567f52

6. Cuthbertson CM, Christophi C. Disturbances of the microcirculation in acute pancreatitis. Br J Surg. 2006;93(5):518-530. doi:10.1002/ bjs. 5316

7. Bhatia M, Wong FL, Cao Y, et al. Pathophysiology of acute pancreatitis. Pancreatology. 2005;5(2-3):132-144. doi:10.1159/000085265

8. Menger MD, Plusczyk T, Vollmar B. Microcirculatory derangements in acute pancreatitis. J Hepatobiliary Pancreat Surg. 2001;8(3):187-194. doi:10.1007/s005340170015

9. Warshaw $A L, O^{\prime}$ Hara PJ. Susceptibility of the pancreas to ischemic injury in shock. Ann Surg. 1978;188(2):197-201. doi:10.1097/00000658197808000-00012

10. Kinnala PJ, Kuttila KT,Grönroos JM,HaviaTV,Nevalainen TJ, NiinikoskiJH. Pancreatic tissue perfusion in experimental acute pancreatitis. Eur J Surg. 2001;167(9):689-694. doi:10.1080/11024150152619345

11. Klar E, Messmer K, Warshaw AL, Herfarth C. Pancreatic ischaemia in experimental acute pancreatitis: Mechanism, significance and therapy. Br J Surg. 1990;77(11):1205-1210. doi:10.1002/bjs.1800771104

12. Vollmar B, Menger MD. Microcirculatory dysfunction in acute pancreatitis. A new concept of pathogenesis involving vasomotion-associated arteriolar constriction and dilation. Pancreatology. 2003;3(3): 181-190. doi:10.1159/000070727

13. Foitzik T, Eibl G, Hotz B, et al. Persistent multiple organ microcirculatory disorders in severe acute pancreatitis: Experimental findings and clinical implications. Dig Dis Sci. 2002;47(1):130-138. doi:10.1023/ a:1013284008219

14. Johns RA, DiFazio CA, Longnecker DE. Lidocaine constricts or dilates rat arterioles in a dose-dependent manner. Anesthesiology. 1985; 62(2):141-144. doi:10.1097/00000542-198502000-00008

15. Kim KH, Lee MG, Kim DG. The cholecystokinin receptor antagonist $\mathrm{L}-364,718$ reduces taurocholate-induced pancreatitis in rats. Int J Pancreatol. 1996;20(3):205-211. doi:10.1007/BF02803770

16. Satoh K, Kamada S, Kumagai M, Sato M, Kuji A, Joh S. Effect of lidocaine on swine lingual and pulmonary arteries. J Anesth. 2015;29(4): 529-534. doi:10.1007/s00540-014-1965-9

17. Newton DJ, McLeod GA, Khan F, Belch JJ. Mechanisms influencing the vasoactive effects of lidocaine in human skin. Anaesthesia. 2007; 62(2):146-150. doi:10.1111/j.1365-2044.2006.04901.x

18. de Klaver MJ, Buckingham MG, Rich GF. Lidocaine attenuates cytokine-induced cell injury in endothelial and vascular smooth muscle cells. Anesth Analg. 2003;97(2):465-470. doi:10.1213/01.ane.000007 3162.27208.e9

19. Piaścik M, Rydzewska G, Milewski J, et al. The results of severe acute pancreatitis treatment with continuous regional arterial infusion of protease inhibitor and antibiotic: A randomized controlled study. Pancreas. 2010;39(6):863-867. doi:10.1097/MPA.0b013e3181d37239

20. Mikami Y, Takeda K, Matsuda K, et al. Rat experimental model of continuous regional arterial infusion of protease inhibitor and its effects on severe acute pancreatitis. Pancreas. 2005;30(3):248-253. doi:10.1097/01.mpa.0000153328.54569.28

21. Manohar M, Verma AK, Venkateshaiah SU, Sanders NL, Mishra A. Pathogenic mechanisms of pancreatitis. World J Gastrointest Pharmacol Ther. 2017;8(1):10-25. doi:10.4292/wjgpt.v8.i1.10

22. Sunamura M, Yamauchi J, Shibuya K, et al. Pancreatic microcirculation in acute pancreatitis. J Hepatobiliary Pancreat Surg. 1998;5(1): 62-68. doi:10.1007/pl00009952

23. Rakonczay Z Jr, Hegyi P, Takács T, McCarroll J, Saluja AK. The role of NF-kappaB activation in the pathogenesis of acute pancreatitis. Gut. 2008;57(2):259-267. doi:10.1136/gut.2007.124115
24. Dawra R, Sah RP, Dudeja V, et al. Intra-acinar trypsinogen activation mediates early stages of pancreatic injury but not inflammation in mice with acute pancreatitis. Gastroenterology. 2011;141(6): 2210-2217.e2. doi:10.1053/j.gastro.2011.08.033

25. Plusczyk T, Witzel B, Menger MD, Schilling M. ETA and ETB receptor function in pancreatitis-associated microcirculatory failure, inflammation, and parenchymal injury. Am J Physiol Gastrointest Liver Physiol. 2003;285(1):G145-G153. doi:10.1152/ajpgi.00181.2002

26. Laude K, Beauchamp P, Thuillez C, Richard V. Endothelial protective effects of preconditioning. Cardiovasc Res. 2002;55(3):466-473. doi:10.1016/s0008-6363(02)00277-8

27. Kusterer K, Poschmann T, Friedemann A, Enghofer M, Zendler S, Usadel KH. Arterial constriction, ischemia-reperfusion, and leukocyte adherence in acute pancreatitis. Am J Physiol. 1993;265(1 Pt 1): G165-G171. doi:10.1152/ajpgi.1993.265.1.G165

28. Plusczyk T, Westermann S, Rathgeb D, Feifel G. Acute pancreatitis in rats: Effects of sodium taurocholate, CCK-8, and Sec on pancreatic microcirculation. Am J Physiol. 1997;272(2 Pt 1):G310-G320. doi:10. 1152/ajpgi.1997.272.2.G310

29. Zhou ZG, Chen YD, Sun W, Chen Z. Pancreatic microcirculatory impairment in experimental acute pancreatitis in rats. World J Gastroenterol. 2002;8(5):933-936. doi:10.3748/wjg.v8.i5.933

30. Ghimire K, Altmann HM, Straub AC, Isenberg JS. Nitric oxide: What's new to NO? Am J Physiol Cell Physiol. 2017;312(3):C254-C262. doi:10. 1152/ajpcell.00315.2016

31. Anderson MC, Schoenfeld FB, lams WB, Suwa M. Circulatory changes in acute pancreatitis. Surg Clin North Am. 1967;47(1):127-140. doi:10. 1016/s0039-6109(16)38138-5

32. Eibl G, Buhr HJ, Foitzik T. Therapy of microcirculatory disorders in severe acute pancreatitis: What mediators should we block? Intensive Care Med. 2002;28(2):139-146. doi:10.1007/s00134-001-1194-1

33. Foitzik T, Eibl G, Hotz HG, Faulhaber J, Kirchengast M, Buhr HJ. Endothelin receptor blockade in severe acute pancreatitis leads to systemic enhancement of microcirculation, stabilization of capillary permeability, and improved survival rates. Surgery. 2000;128(3):399-407. doi:10.1067/msy.2000.107104

34. Aggarwal A, Manrai M, Kochhar R. Fluid resuscitation in acute pancreatitis. World J Gastroenterol. 2014;20(48):18092-18103. doi:10.3748/ wjg.v20.i48.18092

35. Ranson JH, Lackner $H$, Berman IR, Schinella R. The relationship of coagulation factors to clinical complications of acute pancreatitis. Surgery. 1977;81(5):502-511.

36. Ke L, Ni HB, Tong ZH, Li WQ, Li N, Li JS. Efficacy of continuous regional arterial infusion with low-molecular-weight heparin for severe acute pancreatitis in a porcine model. Shock. 2014;41(5):443-448. doi:10. 1097/SHK.0000000000000129

37. Eibl G, Hotz HG, Faulhaber J, Kirchengast M, Buhr HJ, Foitzik T. Effect of endothelin and endothelin receptor blockade on capillary permeability in experimental pancreatitis. Gut. 2000;46(3):390-394. doi:10. $1136 /$ gut.46.3.390

38. Zhou ZG, Chen YD. Influencing factors of pancreatic microcirculatory impairment in acute pancreatitis. World J Gastroenterol. 2002;8(3): 406-412. doi:10.3748/wjg.v8.i3.406

39. Inoue K, Hirota M, Kimura Y, Kuwata K, Ohmuraya M, Ogawa M. Further evidence for endothelin as an important mediator of pancreatic and intestinal ischemia in severe acute pancreatitis. Pancreas. 2003;26(3): 218-223. doi:10.1097/00006676-200304000-00002

40. Singh VK, GardnerTB,Papachristou Gl, etal. An international multicenter study of early intravenous fluid administration and outcome in acute pancreatitis. United European Gastroenterol J. 2017;5(4):491-498. doi:10.1177/2050640616671077 